\title{
LAPORAN KASUS : INFEKSI GIGI SEBAGAI PENYEBAB BAKTEREMIA PADA
} ENDOKARDITIS INFEKTIF

Dian Puspita*, Citra Kiki Krevani

Bagian Kardiologi dan Kedokteran Vaskular Fakultas Kedokteran UniversitasAndalas / RSUP dr M Djamil Padang e-mail:di_poes@yahoo.co.id

\section{KATA KUNCI}

infeksi gigi, endokarditis infektif, Streptococcus viridans

\section{KEYWORDS}

dental infection, infective endocarditis, Streptococcus viridans

\begin{abstract}
ABSTRAK
Pendahuluan: Endokarditis infektif merupakan penyakit yang mematikan dengan angka mortalitas yang tinggi yaitu 20\% dalam 30 hari. Penyebab terjadinya endokarditis infektif pada kasus ini adalah Streptococcus viridans yang merupakan flora oral. Pasien didiagnosis dengan endokarditis infektif definite berdasarkan keluhan, temuan klinis, dan pemeriksaan penunjang. Kasus dan Penatalaksanaan: Keluhan utama pasien adalah demam tinggi sejak 2 minggu sebelum masuk rumah sakit. Demam juga disertai dengan munculnya bintik kemerahan pada kulit dan sesak nafas. Pasien juga mengeluhkan sakit gigi dan berlubang sejak 3 minggu ini, namun tidak berobat. Pada pemeriksaan gigi ditemukan infeksi pada gigi molar 1 dan 2 kanan atas yang berlubang. Pada jantung ditemukan bising pansistolik pada apeks jantung yang menjalar ke aksila. Pada ekokardiografi ditemukan severe mitral regurgitation et causa prolaps Anterior Mitral Leaflet (AML) dengan vegetasi menempel di AML. Pasien diberikan terapi vancomycin $2 \times 500 \mathrm{mg}$ (iv), Gentamicin 1x160 mg. Pemeriksaan kultur darah ditemukan Streptococcus viridans. Streptococcus viridans merupakan bakteri oral yang berkontribusi menimbulkan penyakit endokarditis infektif melalui menyikat gigi, pengunyahan, maupun prosedur gigi. Simpulan: Kebersihan dan kesehatan gigi dan mulut sangat penting untuk dijaga. Selain pasien mempunyai riwayat endokarditis infektif sebelumnya, riwayat katup prostetik, atau penyakit jantung bawaan disarankan untuk diberikan profilaksis antibiotik sebelum dilakukan prosedur gigi.
\end{abstract}

\section{ABSTRACT}

Introduction: Infective endocarditis is a life-threatening disease with an overall mortality rate of $20 \%$ at 30 days. The cause of endocarditis infective in this case is Streptococcus viridans which is an oral flora bacteriae. Patients was diagnosed as definitive infective endocarditis by anamnesis and clinical findings. Case and Management: The main complaint of this patient was a high fever from 2 weeks before admission. Fever was also accompanied by the appearance of reddish spots on the skin and shortness of breath. Patient also complained of toothache and cavities from 3 weeks ago, but did not seek treatment. Dental examination found a dental infection in the right upper first and second molar. Pansystolic murmur was heard at the apex of the heart and radiates to the axilla. Severe mitral regurgitation caused by prolapsed Anterior Mitral Leaflet (AML) with vegetation attached to AML was identified by echocardiography. Patient was treated with 
vancomycin $2 \times 500 \mathrm{mg}$ (iv) and gentamicin $1 \times 160 \mathrm{mg}$ (iv). Blood cultures in this case found Streptococcus viridans. Streptococcus viridians is part of the normal flora of the mouth, usually responsible for infective endocarditis through tooth brushing, mastication, and dental procedures. Conclusion: Maintaining the good oral health and hygiene is very important. Patients with previous infective endocarditis, prosthetic valve, or untreated congenital heart disease who will undergo dental procedures should be considered to get antibiotic prophylaxis.

\section{PENDAHULUAN}

Endokarditis infektif (EI) adalah infeksi pada lapisan endokardial jantung, termasuk katup jantung. ${ }^{1}$ Endokarditis infektif merupakan penyakit yang mematikan, walaupun sudah terjadi peningkatan manajemen terapi, namun endokarditis infektif tetap memiliki angka mortalitas yang tinggi yaitu $20 \%$ dalam 30 hari. ${ }^{2,3}$

Ada tiga faktor yang berkontribusi terhadap pengembangan endokarditis infektif yaitu masuknya bakteri ke dalam aliran darah, adanya gangguan pada katup jantung, dan virulensi bakteri. Karena katup yang sudah ada sebelumnya mengalami gangguan (seperti cacat bawaan, penyakit jantung rematik atau katup jantung prostetik), terbentuklah trombus yang steril. Trombus inilah tempat menempel bakteri yang akhirnya membentuk vegetasi. Peningkatan jumlah bakteri dari aliran darah akan memperbesar vegetasi dan mengganggu fungsi valvular. Akhirnya vegetasi ini dapat menyebabkan gagal jantung kongestif. ${ }^{4}$

Bakteri oral dapat masuk ke dalam aliran darah dari gigi yang terinfeksi dengan cara menyikat gigi, mengunyah, atau prosedur gigi. Staphylococcus aureus dan
Streptococcus viridans dapat hadir di rongga mulut dan merupakan organisme paling umum yang menyebabkan terjadinya endokarditis infektif. $^{5}$

\section{KASUS DAN PENATALAKSANAAN}

Seorang wanita usia 24 tahun datang ke Poliklinik Jantung dan Pembuluh Darah RSUP Dr. M Djamil Padang dengan keluhan demam sejak 2 minggu sebelum masuk rumah sakit. Demam tinggi, terus menerus, tidak menggigil. Riwayat muncul bintik kemerahan di kulit dalam 2 minggu sebelum masuk rumah sakit. Bercak sudah ada sejak 2 bulan yang lalu, awalnya bercak sebesar jarum pentul lalu makin lama makin banyak dan bertambah besar.

Pasien juga mengeluh sesak nafas sejak 2 minggu sebelum masuk rumah sakit, semakin memberat sejak 3 hari sebelum masuk rumah sakit. Sesak nafas hilang timbul, tidak disertai bunyi menciut, dan tidak dipengaruhi oleh makanan. Sesak nafas memberat dengan aktivitas dan berkurang dengan istirahat. Terdapat riwayat terbangun di malam hari karena sesak nafas, pasien cenderung tidur dengan 2-3 bantal. Pasien juga mengeluhkan sakit gigi sejak 3 minggu ini. Terdapat 
riwayat gigi berlubang, namun pasien tidak berobat. Riwayat pencabutan gigi disangkal.

Pada pemeriksaan fisik didapatkan keadaan umum sakit sedang, kesadaran kompos mentis, tekanan darah 96/62 mmHg, nadi 84 kali/menit teratur dan kuat angkat, pernafasan $24 \mathrm{kali} / \mathrm{menit}$, suhu $38,4^{\circ} \mathrm{C}$. Pada pemeriksaan gigi dan mulut, tampak gigi 6-7 kanan atas berlubang. Pada pemeriksaan fisik jantung, iktus cordis teraba 1 jari lateral RIC (ruang intercosta) VI linea mid klavikularis kiri, thrill tidak teraba. Pada pemeriksaan auskultasi didapatkan bunyi jantung 1 dan 2 teratur, dan terdengar murmur pansistolik di apeks jantung grade 3/6 menjalar ke aksila. Pada pemeriksaan fisik paru terdengar ronkhi basah halus di basal kedua lapangan paru, wheezing tidak terdengar.

Pada pemeriksaan laboratorium ditemukan kadar haemoglobin 10,3 gr/dL, leukosit 12.590/mm3, hematokrit 29\%, trombosit 202.000/mm3, kadar ureum $24 \mathrm{mg} / \mathrm{dL}$, kreatinin $0,8 \mathrm{mg} / \mathrm{dL}$, Creatinine Clearance $(\mathrm{CrCl}) \quad 109,79 \mathrm{~mL} / \mathrm{menit}$, kadar elektrolit kalsium 8,8 mg/dL, natrium $132 \mathrm{mmol} / \mathrm{l}$, kalium 3,9 $\mathrm{mmol} / \mathrm{l}$, klorida $106 \mathrm{mmol} / \mathrm{L}$, sehingga didapatkan kesan leukositosis. Pada urinalisis didapatkan kesan proteinuria positif $(+)$.

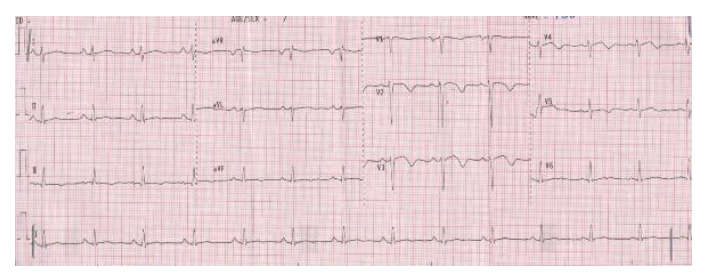

Gambar 1. EKG pada hari pertama rawatan
Pada pemeriksaan elektrokardiografi (EKG) ditemukan irama sinus dengan laju QRS 85x/ menit, Axis normal, Gelombang $\mathrm{P}$ normal, PR interval 0.08 detik, durasi QRS 0.04 detik, terdapat gelombang $\mathrm{T}$ inverted di V14, tidak ditemukan hipertrofi ventrikel kanan dan ventrikel kiri, QTc 413 ms (Gambar 1). Pada pemeriksaan rontgen toraks didapatkan CTR 65\%, segmen aorta normal, segmen pulmonal normal, pinggang jantung mendatar, tidak ditemukan kranialisasi dan infiltrat (Gambar 2).

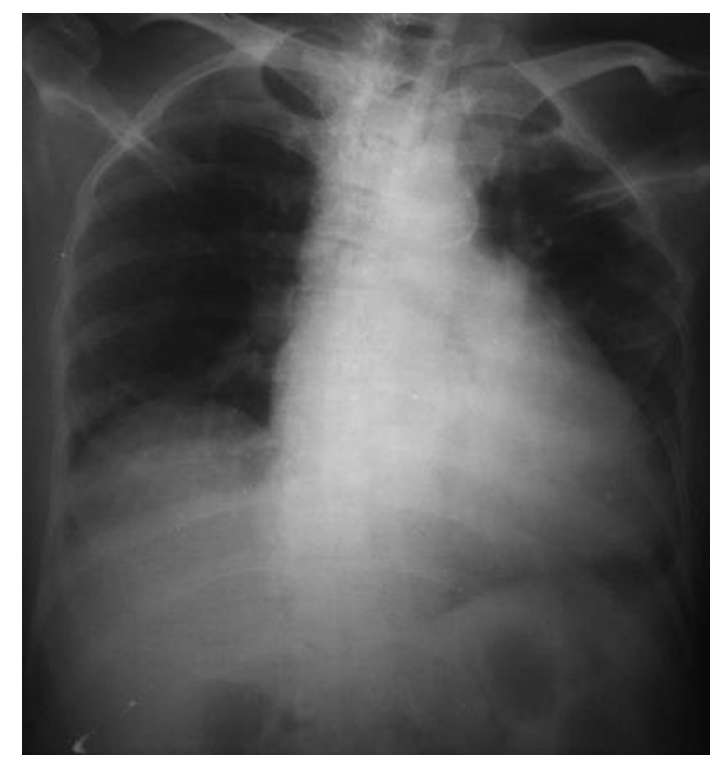

Gambar 2. Rontgen toraks pasien

Pada pemeriksaan ekokardiografi pada hari pertama rawatan didapatkan MR Severe ec prolaps Anterior Mitral Valve (AML) dengan vegetasi menempel di AML dengan diameter $0,6 \times 1,8 \mathrm{~cm}$ (area $1.1 \mathrm{~cm}^{2}$ ), fungsi sistolik global LV baik, EF 67\%, global normokinetik, fungsi diastolik LV tidak bias dinilai karena MR Severe, katup lain baik dan kontraktilitas RV baik (Gambar 3). 


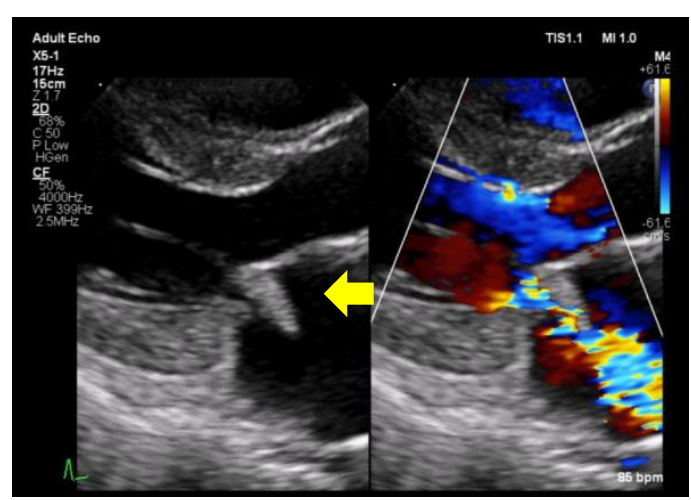

Gambar 3. Ekokardiografi pasien: panah kuning menunjukkan gambaran vegetatif pada AML.

Pasien dikonsulkan ke bagian Gigi dan Mulut, THT-KL, dan Mata. Pada bagian gigi dan mulut ditemukan fokal infeksi pada gigi molar 1 dan 2 kanan atas yang berlubang. Dengan anjuran ekstraksi gigi. Pada konsul ke bagian THT-KL tidak ditemukan fokal infeksi dan pada bagian mata tidak ditemukan adanya Roth spot.

Berdasarkan anamnesis, pemeriksaan fisik dan pemeriksaan penunjang tersebut, pasien didiagnosis dengan Endokarditis infektif Possible dan Mitral Regurgitation (MR) NYHA f.c. III, nekrosis pulpa.

Pengambilan sampel darah pasien segera dilakukan untuk pemeriksaan kultur darah dan sensitivity test sebelum diberikan antibiotik. Pengambilan sampel dilakukan melalui pungsi pada 4 lokasi yang berbeda, yaitu arteri femoralis dekstra, arteri femoralis sinistra, vena mediana cubitid ekstra dan vena mediana cubiti sinistra. Interval pengambilan sampel darah pertama dan yang terakhir adalah 1 jam. Setelah pengambilan sampel darah, pasien diberikan terapi antibiotik empiris Ampicilin sulbactam dan Gentamicin. Terapi yang diberikan pada pasien pada hari pertama rawatan adalah IVFD RL 500 cc/24 jam, injeksi Ampicillin sulbactam 4x3 gram, injeksi Gentamicin 1x160 mg, injeksi Furosemide 2x20 mg, Ramipril 1x2,5 mg, Spironolakton 1x25 mg, Paracetamol 3x750 mg.

Pada hari rawatan keenam hasil pemeriksaan kultur darah didapatkan kesan bakteri terisolasi signifikan sebagai penyebab infeksi, yaitu bakteri Streptococcus Viridans. Berdasarkan sensitivity test, pasien diketahui sensitive terhadap Vancomicyn, Cotrimoxazole, Gentamicin, Fosfomycin, Levofloxacin, Eryhtromycin, Cefotaxime, Ciprofloxacin, Cefoxitin, dan Oxacillin, namun resisten terhadap Ampicillin, Amoxicillin, Chloramphenicol, Ampicillin Sulbactam, dan Tetracycline.

Pasien kemudian didiagnosis sebagai Endokarditis infektif Definite, MR Severe NYHA fc II. Pada terapi antibiotik, pasien selanjutnya diberikan injeksi Vancomycin 2x500 mg dan injeksi Gentamicin 1x160 mg, sedangkan injeksi Ampicillin dihentikan. Terapi lainnya dilanjutkan, Furosemid 2x20 mg, Ramipril 1x5 mg, Spironolakton $1 \times 25 \mathrm{mg}$.

\section{PEMBAHASAN}

Seorang wanita 24 tahun didiagnosis dengan Endokarditis infektif Definite yang disebabkan oleh Streptococcus Viridans. Endokarditis infektif merupakan penyakit yang disebabkan oleh infeksi mikroba pada lapisan endotel jantung. Infeksi ini paling 
sering terjadi pada satu atau lebih daun katup jantung (leaflet), namun infeksi juga dapat meluas hingga mural endokardium, kordae, miokardium, dan pericardium. ${ }^{6}$

Gambaran klinis endokarditis seringkali ditemukan tidak spesifik. Namun, pada pasien dengan demam dan kelainan pada katup atau terdapat faktor predisposisi yang diketahui berhubungan dengan EI, harus dilakukan pemeriksaan lebih lanjut untuk menentukan diagnosis EI. ${ }^{7}$

Gejala dan tanda yang paling sering ditemukan pada pasien EI adalah demam (Tabel1). ${ }^{1}$ Pada pasien ini, didapatkan keluhan utama berupa demam tinggi dan sesak nafas sejak 2 minggu sebelum masuk rumah sakit. Sesak nafas ditemukan mengarah pada gangguan jantung, yaitu dengan sesak nafas ketika beraktivitas, orthopnea, dan paroxysmal nocturnal dyspnea.

Berdasarkan anamnesis, pasien memiliki faktor predisposisi berupa riwayat sakit gigi dan gigi berlubang yang tidak pernah diperiksakan maupun diobati. Berdasarkan data epidemiologi yang telah ada, faktor predisposisi utama di negara berkembang adalah penyakit jantung reumatik dengan Streptococcus viridans sebagai penyebab infeksi utama pada bagian gigi. ${ }^{6}$ Sedangkan infeksi Staphylococcusaureus akibat paparan infeksi setelah tindakan medis lebih banyak ditemukan di negara maju. ${ }^{7}$ Pada pemeriksaan tanda vital ditemukan sesak nafas (frekuensi nafas $24 \mathrm{x} /$ menit) dan
Tabel 1. Gejala dan Tanda pada endocarditis infektif. ${ }^{1}$

\begin{tabular}{lc}
\hline \multicolumn{1}{c}{ Gejala } & $\begin{array}{c}\text { Jumlah Pasien } \\
(\mathbf{\%})\end{array}$ \\
\hline Demam & $80-95$ \\
Menggigil & $40-70$ \\
Lemah & $40-50$ \\
Malaise & $20-40$ \\
Berkeringat & $20-40$ \\
Anorexia & $20-40$ \\
Nyeri kepala & $20-40$ \\
Dispnea & $20-40$ \\
Batuk & $20-30$ \\
Penurunan berat badan & $20-30$ \\
Mialgia/artalgia & $10-30$ \\
Stroke & $10-20$ \\
Delirium & $10-20$ \\
Mual / muntah & $10-20$ \\
Edema & $5-15$ \\
Nyeri dada & $5-15$ \\
Nyeri perut & $5-15$ \\
Hemoptisis & $5-10$ \\
Nyeri pinggang & $5-10$ \\
\hline
\end{tabular}

suhu tubuh yang meningkat $\left(38,4^{\circ} \mathrm{C}\right)$. Pada pemeriksaan gigi ditemukan infeksi pada gigi molar 1 dan 2 kanan atas yang berlubang. Pada jantung ditemukan bising pansistolik pada apeks jantung yang menjalar ke aksila, yang mana merupakan ciri khas dari mitral regurgitasi ${ }^{8}$ sehingga dibutuhkan pemeriksaan ekokardiografi untuk mengetahui penyebab bising. Sesuai yang didapatkan pada pasien, temuan paling sering pada pemeriksaan fisikpasien EI adalah demam dan bising jantung (Tabel 2), sedangkan tanda khas lainnya seperti splinter hemorrhage, janeway lesion, osler nodes dan roth spot tidak ditemukan pada pasien ini.

Pemeriksaan ekokardiografi menunjukkan MR Severe ec Prolaps AML dengan vegetasi menempel di AML. Vegetasi didefinisikan sebagai massa intrakardiak yang berosilasi ataupun tidak berosilasi pada katup, struktur endokardial lainnya, atau pun pada alat yang diimplantasikan pada bagian intrakardiak. ${ }^{9}$ 
Pemeriksaan kultur darah didapatkan hasil pemeriksaan adalah Streptococcus Viridans.

Tabel 2. Temuan Pemeriksaan Fisik pada Endokarditis

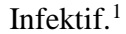

\begin{tabular}{lc}
\hline \multicolumn{1}{c}{ Tanda } & $\begin{array}{c}\text { Jumlah pasien } \\
(\boldsymbol{\%})\end{array}$ \\
\hline Demam & $80-90$ \\
Murmur jantung & $75-85$ \\
Murmur baru & $10-50$ \\
Murmur yang berubah & $5-20$ \\
Saraf pusat yang abnormal & $20-40$ \\
Splenomegali & $10-40$ \\
Peteki/ perdarahan & $10-40$ \\
konjungtiva & \\
Splinter hemorrhage & $5-15$ \\
Lesi janeway & $5-10$ \\
Nodus osler & $3-10$ \\
Lesi retina atau roth & $2-10$ \\
\hline
\end{tabular}

Tabel 3. Definisi dari terminologi dalam kriteria Duke yang dimodifikasi untuk diagnosis endokarditis infektif $^{9}$

\begin{tabular}{l}
\hline Kriteria Mayor \\
\hline Kultur darah positif untuk EI \\
Mikroorganisme khas yang konsisten dengan EI \\
dari 2 kultur darah yang terpisah: Viridans \\
streptococci, Streptococcus bovis, kelompok \\
HACEK, Staphylococcus aureus atau \\
Community-acquired enterococci, tanpa adanya \\
focus primer \\
Mikroorganisme yang konsisten dengan EI dari \\
kultur darah positif yang persisten, didefinisikan \\
sebagai berikut: \\
Setidaknya 2 kultur positif sampel darah diambil \\
terpisah >12 jam; \\
atau \\
Semua atau mayoritas dari $\geq 4$ kultur darah \\
terpisah (dengan pengambilan sampel darah \\
pertama dan terakhir setidaknya berjarak 1 jam) \\
Satu kultur darah yang positif untuk Coxiella \\
burnetiid atau titer anti phase I \\
Antibody IgG > $1: 800$ \\
\hline Bukti keterlibatan endocardial \\
\hline Positif echocardiogram untuk EI (TEE \\
direkomendasikan untuk pasien dengan katup \\
prostetik, setidaknya termasuk Possible EI secara \\
kriteria klinis atau EI dengan komplikasi (abses \\
paravalvular); TTE pemeriksaan pertama pada \\
pasien lainnya, didefinisikan sebagai berikut: \\
Massa intrakardiak pada katup atau struktur \\
penunjang, pada jalur jet regurgitant atau pada \\
bahan implant tanpa adanya penjelasan anatomi \\
alternatif, atau Abses, atau Dehisens parsial baru \\
dari katup prostetik, \\
\hline
\end{tabular}

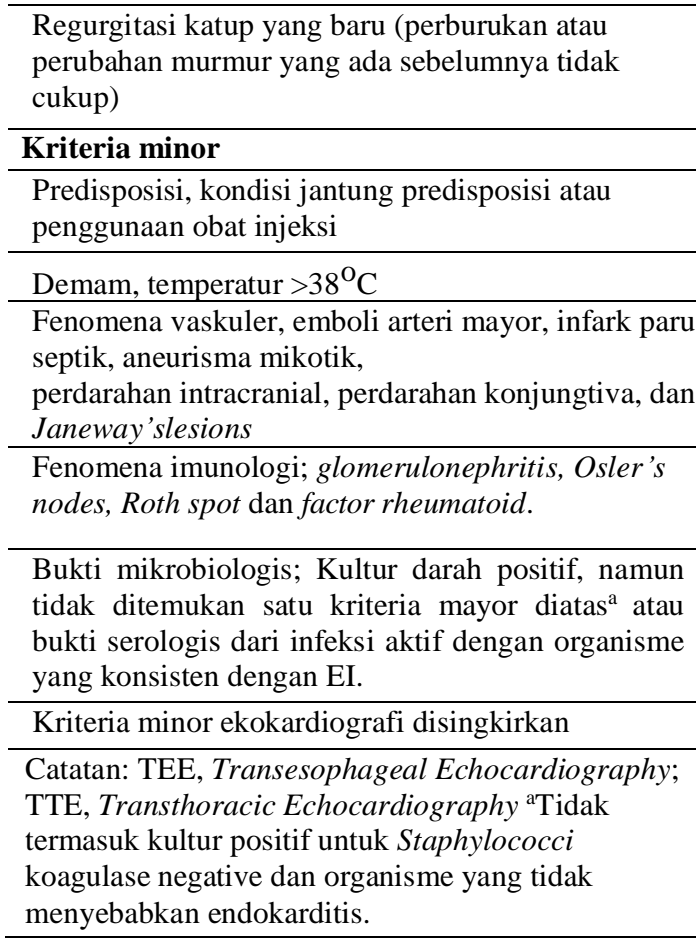

Berdasarkan temuan dari anamnesis, pemeriksaan fisik, pemeriksaan penunjang pada pasien, berdasarkan definisi yang digunakan dalam kriteria Duke yang dimodifikasi (Tabel 3) ${ }^{9}$ untuk diagnosis endokarditis infektif, didapatkan 1 kriteria mayor, yaitu vegetasi yang diketahui melalui pemeriksaan ekokardiografi dan 1 kriteria minor, yaitu demam $>38,4^{\circ} \mathrm{C}$. Oleh karena itu, menurut kriteria Duke yang dimodifikasi (Tabel 4), ${ }^{9}$ pasien didiagnosis dengan Endokarditis infektif definite.

Berdasarkan hasil kultur darah dan konsul dari bagian gigi dan mulut, dicurigai penyebab infeksi pada pasien ini adalah dari infeksi gigi. Kesehatan gigi yang buruk maupun prosedur pada gigi, diketahui berhubungan dengan infeksi Streptococcus viridans. ${ }^{1}$ 
Tabel 4. Definisi endokarditis infektif menurut kriteria Duke yang dimodifikasi ${ }^{9}$

\begin{tabular}{l} 
Endokarditis infektif Definite \\
\hline Kriteria patologis \\
- Mikroorganisme yang ditunjukkan dengan kultur \\
atau pemeriksaan histologis dari vegetasi, vegetasi \\
yang sudah diembolisasi, atau specimen abses \\
intrakardiak, atau \\
- Lesi patologis, vegetasi atau abses intrakardiak \\
yang dikonfirmasi dengan pemeriksaan histologi \\
menunjukkan endokarditis aktif. \\
Kriteria Klinis \\
- 2 kriteria mayor; atau \\
- 5 kriteria mayor dan 3 kriteria minor; atau minor \\
\hline
\end{tabular}

- kriteria mayor dan 1 kriteria minor; atau

- 3 kriteria minor

- Diagnosis alternatif yang jelas

- Resolusi dari gejala yang menunjukkan EI, dengan terapi antibiotik selama $\leq 4$ hari; atau

- Tidak ada bukti patologis dari EI pada pembedahan atau autopsi, dengan terapi antibiotik selama $\leq 4$ hari

- Tidak ditemukan kriteria untuk EI Possible seperti di atas

Streptococcus viridans, kelompok heterogen dari alpha-hemolytic strepto-cocci, merupakan bagian dari flora normal dari mulut, biasanya bertanggung jawab atas karies gigi, perikoronitis, serta endokarditis infektif subakut. Streptococcus viridans bertanggung jawab atas 40\% hingga $60 \%$ kasus endokarditis infektif. Endokarditis infektif yang berhubungan dengan Streptococcus viridans biasanya mengalami mitral valve prolapse. ${ }^{10}$

Bakteremia adalah konsekuensi dari infeksi rongga mulut yang menyebabkan endokarditis infektif. ${ }^{10}$ Hubungan antara oral bakteri dan endokarditis infektif telah menjadi topik banyak penelitian selama bertahun-tahun. Awalnya, pada tahun 1909, studi Horder disorot bahwa 'sepsis oral' merupakan faktor penting dalam perkembangan endokarditis infektif. ${ }^{11}$ Namun, sejak itu, sebagian besar fokus diberikan pada pencegahan bakteremia, dengan menghindari melakukan prosedur gigi invasif seperti sebagai ekstraksi dan scaling dalam. Banyak penelitian telah menunjukkan bahwa bakteremia oleh flora oral dapat disebabkan oleh pencabutan gigi, sehingga menganjurkan penggunaan antibiotik sebelum dilakukan prosedur pada gigi. ${ }^{5,12,13}$ Pada Maret 2008, panduan National Institute of Clinical Excellence (NICE) mengeluarkan pernyataan bahwa profilaksis antibiotik tidak perlu. Hal ini disebabkan karena ditemukan penelitian lebih lanjut yang menunjukkan bahwa bakteremia terjadi akibat aktivitas seharihari, seperti menyikat gigi dan pengunyahan, dimana menimbulkan risiko lebih besar bagi pasien daripada bakteremia yang berhubungan dengan prosedur gigi invasif. ${ }^{14,15}$

Berdasarkan 2015 ESC Guidelines for the management of infective endocarditis, pemberian profilaksis antibiotik sebelum prosedur gigi diberikan pada pasien dengan risiko tinggi. Prosedur gigi yang dipertimbangkan mendapatkan profilaksis antibiotik yaitu prosedur gigi yang membutuhkan manipulasi gingiva atau di regio periapikal gigi atau perforasi mukosa mulut. Sedangkan kategori pasien risiko 
tinggi terdiri dari tiga kategori, yaitu: ${ }^{9}$

1. Pasien yang menggunakan katup prostetik atau dengan penggunaan material prostetik untuk memperbaiki katup,

2. Pasien dengan riwayat EI sebelumnya,

3. Pasien dengan penyakit jantung kongenital yang tidak diobati atau baru menjalani prosedur operasi paliatif shunts, conduits, atau prostese lainnnya.

Sasaran utama untuk profilaksis antibiotik adalah streptokokus oral. Tabel 5 merangkum rejimen utama profilaksis antibiotik yang dianjurkan sebelum prosedur gigi. Fluoroquinolon dan glikopeptida tidak dianjurkan karena kemanjuran mereka yang tidak jelas dan potensi terjadinya resistansi.

Tabel 5. Regimen profilaksis antibiotik sebelum dilakukan prosedur gigi pada pasien yang beresiko tinggi

\begin{tabular}{l|l|l|l}
\hline Situasi & Antibiotik & \multicolumn{3}{l}{$\begin{array}{l}\text { Dosis tunggal 30-60 } \\
\text { menit } \\
\text { prosedur }\end{array}$} \\
\cline { 3 - 4 } & & Dewasa & Anak \\
\hline Tidak & Amoksisilin & 2 gram & $50 \quad \mathrm{mg} /$ \\
alergi & atau & secara & kgbb \\
penisilin & ampisilin a & oral atau & secara \\
atau & & iv & oral atau \\
ampisilin & & iv & 20 \\
Alergi & Klindamisin & $600 \quad$ mg & mg/kgbb \\
penisilin & & secara & secara \\
atau & & oral atau & oral atau \\
ampisilin & & iv & iv \\
& & &
\end{tabular}

Tatalaksana yang diberikan pada pasien sesuai dengan ESC Guidelines for the management of infective endocarditis. Sebelum hasil pemeriksaan kultur darah pada pasien diketahui, pasien ditatalaksana dengan pemberian antibiotik empirik pada kasus EI yang hanya melibatkan katup (katup asli/ native), yaitu: ${ }^{16}$
1. Ampicillin Sulbactam $12 \mathrm{gram} / \mathrm{hari}$ intravena terbagi dalam 4 dosis atau Amoxillin Clavulanate $12 \mathrm{gram} / \mathrm{hari}$ intravena dalam 4 dosis selama 4-6 minggu, ditambah dengan

2. Gentamicin $3 \mathrm{mg} / \mathrm{kg} / \mathrm{hari}$ intravena atau intramuskular terbagi dalam 2-3 dosis.

Pemberian terapi antibiotik empirik dapat diberikan selama 4-6 minggu. ${ }^{16}$ Pada pasien ini, terapi empirik diberikan hingga hasil kultur darah dan sensitivity test didapatkan. Pemberian Ampicillin Sulbactam pada pasien dihentikan karena ditemukannya resistensi dan terapi antibiotik kemudian diberikan sesuai temuan bakteri pada kultur darah dan sensitivity test. Vancomycin diberikan dalam dosis $30-60 \mathrm{mg} / \mathrm{kgbb} /$ hari dibagi dalam 2-3 dosis selama 4-6 minggu. ${ }^{9}$

Vancomycin hanya aktif terhadap kuman Gram positif, khususnya golongan kokus, sehingga penggunaannya dapat dikombinasikan dengan Gentamicin atau golongan aminoglikosida lainnya. ${ }^{17}$ Beberapa studi telah menunjukkan bahwa kombinasi Vancomycin dan Gentamicin memberikan efek sinergis dalam mengatasi baik infeksi methicillin-susceptible Staphylococcus aureus (MSSA), maupun methicillinresistant Staphylococcus aureus (MRSA), terutama pada infeksi yang tidak teratasi dengan Vancomycin saja. ${ }^{15}$ Sesuai dengan penelitian sebelumnya, Tsuji et al (2005) lebih lanjut menemukan bahwa pemberian Vancomycin saja tidak memberikan efek bakterisid terhadap MMSA maupun MRSA, 
namun kombinasinya dengan Gentamycin meningkatkan efeknya dengan signifikan dan dapat membunuh 99,9 \% Streptococcus viridans. ${ }^{18}$ Oleh karena itu, pemberian Gentamicin intravena tetap dilanjutkan dan dikombinasikan dengan Vancomycin intravena.

Untuk mencegah terjadinya kembali infeksi, pasien diedukasi berdasarkan 2015 ESC Guidelines for the management of infective endocarditis (Tabel 6). Pasien pada kasus ini termasuk dari pasien dengan risiko tinggi.

Tabel 6. Tindakan preventif non-spesifik pada pasien risiko menengah dan tinggi ${ }^{9}$

\begin{tabular}{ll}
\hline $\begin{array}{l}\text { Anjuran ini berlaku untuk populasi umum dan } \\
\text { harus ditekankan pada pasien dengan risiko tinggi }\end{array}$ \\
\hline - $\begin{array}{l}\text { Menjaga kebersihan gigi dan mulut dengan } \\
\text { sangat berhati-hati. Pemeriksaan gigi harus } \\
\text { dilakukan dua kali sehari pada pasien risiko } \\
\text { tinggi dan sekali setahun pada populasi umum } \\
\text { dan pasien dengan risiko rendah atau menengah. }\end{array}$ \\
\hline - & Disinfeksi luka. \\
\hline - & $\begin{array}{l}\text { Eradikasi atau menurunkan infeksi kronis bakteri } \\
\text { pada kulit dan urin. }\end{array}$ \\
\hline Antibiotik kuratif pada semua fokus infeksi \\
bakteri.
\end{tabular}

\section{SIMPULAN}

Menjaga kesehatan serta kebersihan gigi dan mulut sangat penting untuk kesehatan pasien. Pemeriksaan gigi harus dilakukan dua kali sehari pada pasien risiko tinggi dan sekali setahun pada populasi umum dan pasien dengan risiko rendah atau menengah.

Bakteri oral dapat menimbulkan penyakit endokarditis infektif. Bakteri oral dapat masuk ke aliran darah melalui menyikat gigi, pengunyahan, maupun prosedur gigi. Oleh karena itu, pada pasien dengan riwayat endokarditis infektif sebelumnya, riwayat katup prostetik, atau penyakit jantung bawaan disarankan untuk diberikan profilaksis antibiotik sebelum dilakukan prosedur gigi.

\section{DAFTAR PUSTAKA}

1. Karchmer AW. Infective endocarditis. In: Libby P, Bonow RO, Mann DL, Zipes DP, editor. Braunwald's Heart Disease: A Textbook of Cardiovascular Medicine. $11^{\text {th }}$ ed. Philadelphia: Saunders Elsevier; 2018:1483-1502.

2. Vincent LL, Otto CM. Infective endocarditis: update on epidemiology, outcomes, and management. Curr Cardiol Rep.2018; 86: 1-9.

3. Slipczuk L, Codolosa JN, Davila CD, Romero-Corral A. Yun J, Pressman GS, et al. Infective endocarditis epidemiology overfive decades: a systematic review. PLoS One. 2013; 8 (12): e82665.

4. Keynan Y, Rubinstein E. Pathophysiology ofinfective endocarditis. Curr Infect Dis Rep.2013;15: 342-346.

5. Thornhill MH. Infective endocarditis: theimpact of the NICE guidelines for antibiotic prophylaxis. Dent Update. 2012; 39: 6-10.

6. Haldar SM, O'Gara PT. Infective endocarditis. In : Hurst JW, Walsh RA, Fang JC, Fuster V, editor. Hurst's The Heart: Manual of cardiology. $13^{\text {th }}$ ed. New York; London: McGraw-Hill Medical; 2013: 424449

7. Karchmer AW. Infective endocarditis. In: Loscalzo J, edition. Harrison's cardiovascular medicine. $2^{\text {nd }}$ ed.New York; London: McGraw Hill Medical; 2012: 294308.

8. Bickley LS, Bates B, Szilagyi PG. Bates' pocket guide to physical examination 
andhistory taking. Philadelphia: Wolters Kluwer Health/Lippincott Williams and Wilkins;2013.

9. Habib G, Lancellotti P, Antunes MJ, Bongiorni MG, Casalta JP, Zotti FD, et al. 2015 ESC Guidelines for the management of infective endocarditis. European Heart Journal. 2015;36(44):3075-3128.

10. Birlutiu V, Birlutiu RM, Costache VS. Viridans streptococcal infective endocarditis associated with fixed orthodontic appliance managed surgically by mitral valve plasty. Medicine.2018; 97:27.

11. Horder TJ. Infective endocarditis with ananalysis of 150 cases and with special referenceto the chronic form of the disease. Quart J Med. 1909; 2: 289-324.

12. Lockhart PB, Brennan MT, Sasser HC, Fox PC, Paster BJ, Bahrani-Mougeot FK. Bacteremia associated with toothbrushing and dental extraction. Circulation. 2008; 117:3118-3125.

13. Duval X, Alla F, Hoen B, Danielou F, Larrieu S, Delahaye F, et al. Estimated risk of endocarditis in adults with predisposing cardiac conditions undergoing dental procedures with or without antibiotic prophylaxis. Clin InfectDis. 2006; 42: e102e107.

14. Thornhill MH, Lockhart PB, Prendergast B, Chambers JB, Shanson D. NICE and antibiotic prophylaxis to prevent endocarditis. Br Dent J. 2015; 218: 619-621.

15. Lockhart PB, Brennan MT, Thornhill MH et al. Poor oral hygiene as a risk factor for infective endocarditis-related bacteraemia. J Am DentAssoc. 2009; 140: 1238-1244.

16. Habib G, Hoen B, Tornos P, Thuny F, Prendergast B, Vilacosta I. Guidelines on the prevention, diagnosis, and treatment of infective endocarditis (new version 2009). European Heart Journal. 2009; 30: 23692413.

17. Farmakologi dan Terapi. 4 ed. Jakarta: Fakultas Kedokteran Universitas Indonesia; 2001.

18. Tsuji BT, Rybak MJ. Short-course gentamicin in combination with daptomycin orvancomycin against Staphylococcus aureus in an in vitro pharmacodynamic modelwith simulated endocardial vegetations. Antimicrob Agents Chemother. Jul 2005; 49 (7): 2735-2745 